\title{
TENDÊNCIAS CLIMÁTICAS E A INCIDÊNCIA DA DENGUE EM CIDADES DO SUL DO BRASIL: ESTUDO DE CASO DE LONDRINA, MARINGÁ (PR) E FLORIANÓPOLIS (SC) ${ }^{1}$.
}

\author{
ELY, Deise Fabiana - deise@uel.br \\ Geógrafa - Professora Adjunto do Departamento de Geociências da Universidade \\ Estadual de Londrina (UEL)
}

\begin{abstract}
RESUMO: No contexto atual, a dengue constitui um dos principais problemas de saúde pública no Brasil e no mundo, pois faz anual e sazonalmente centenas de milhares de vítimas. $\mathrm{O}$ presente artigo tem como objetivo principal analisar as tendências climáticas nas cidades de Londrina, Maringá (PR) e Florianópolis (SC) com o intuito de compreender a correlação das condições climáticas com a incidência da dengue no sul do Brasil. Para tanto, os dados de temperatura média e precipitação foram organizados em gráficos e tabelas para o período de 1983 a 2010 e submetidos aos testes estatísticos da regressão linear, Mann-Kendall e Pettitt. Também foram elaborados gráficos para a representação das notificações dos primeiros sintomas dos casos de dengue em conjunto com os totais pluviométricos e as médias térmicas mensais para o período de 2007 a 2010, submetidos ao teste de correlação de Pearson. Foram observadas tendências positivas nas precipitações de Londrina e Florianópolis, mas negativas para Maringá. Os testes de Mann-Kendall e Pettitt revelaram não ocorrer mudanças significativas nas precipitações anuais das três localidades. Com relação à variabilidade das temperaturas médias, a regressão linear indica tendências positivas para todas as localidades; enquanto que o teste de Mann-Kendall aponta tendências positivas para as temperaturas médias de Maringá e Florianópolis e para as médias das mínimas de Londrina. Foi verificada uma correlação temporal entre a eclosão dos casos de dengue após períodos chuvosos e temperaturas médias entre 17 e $27^{\circ} \mathrm{C}$ e que as condições climáticas de Florianópolis têm dificultado a reprodução e sobrevivência do vetor da dengue.
\end{abstract}

Palavras-chave: Tendências climáticas; Dengue; sul do Brasil.

CLIMATE TENDENCIES AND THE OCCURRENCE OF DENGUE IN CITIES OF SOUTHERN BRAZIL: A CASE STUDY OF LONDRINA, MARINGÁ (PR) AND FLORIANÓPOLIS (SC).

ABSTRACT: Dengue is one of the main public health problems in Brazil and in the rest of the world today, making hundreds of thousands of victims every year. This article aims at analyzing climate tendencies in three Brazilian cities, Londrina (PR), Maringá (PR) and Florianópolis (SC), in order to understand the correlation of climatic conditions with the incidence of dengue in southern Brazil. Accordingly, it presents figures and tables of mean temperature and precipitation data from 1983 to 2010 and the statistical analysis of the linear regression, Mann-Kendall and Pettitt. Were also designed graphics for the representation of the notifications of the first symptoms of dengue cases in conjunction with the total monthly rainfall and temperature regimes for the period 2007 to 2010, subject to the Pearson correlation test. We observed positive tendencies in precipitation of Florianópolis and Londrina, but negative for Maringá. The Mann-Kendall and Pettitt revealed no significant changes occur in the annual rainfall of the three cities. With regard to the variability of average temperatures, linear regression indicates positive tendencies for all locations, whereas the Mann-Kendall shows positive tendencies for the average temperatures of Maringá and Florianópolis and for the Londrina's mean minimum. The data show a temporal correlation between dengue occurrence after raining periods and mean temperature of 17 to $27^{\circ} \mathrm{C}$, authors observed that Florianópolis' climate conditions, up to now, have contributed to disrupt the reproduction and surviving of the mosquito Aedes aegypti.

Keywords: climate tendencies; Dengue; southern Brazil.

\footnotetext{
${ }^{1}$ Pesquisa financiada pelo CNPq, número do processo 400594/2010.
} 
TENDENCIAS CLIMÁTICAS Y LA INCIDENCIA DE LA DENGUE EN CIUDADES DEL SUR DEL BRASIL: ESTUDIO DEL CASO DE LONDRINA, MARINGÁ (PR) Y FLORIANÓPOLIS (SC).

Resumen: En el contexto actual, la dengue constituye uno de los principales problemas de salud pública en el Brasil y en el mundo, pues hace anual y sazonalmente centenas de millares de víctimas. El presente artículo tiene como objetivo principal analizar las tendencias climáticas en las ciudades de Londrina y Maringá (PR) y Florianópolis (SC) con el intuito de comprender la correlación de las condiciones climáticas con la incidencia de la dengue en el sur del Brasil. Para tanto, los datos de temperatura media y precipitación fueron organizados en gráficos y tablas para el período de 1983 hasta 2010 y sometidos a los tests estadísticos de la regresión linear, Mann-Kendall y Pettitt. También fueron elaborados gráficos para la representación de las notificaciones de los primeros síntomas de los casos de dengue en conjunto con los totales pluviométricos y medias térmicas mensuales para el período de 2007 hasta 2010, sometidos al test de correlación de Pearson. Fueron observadas tendencias positivas en las precipitaciones de Londrina y Florianópolis, pero negativas para Maringá. Y los tests de Mann-Kendall y Pettitt revelaran no ocurrir mudanzas significativas en las precipitaciones anuales de las tres localidades. Con relación a la variabilidad de las temperaturas medias, la regresión linear indica tendencias positivas para todas las localidades; mientras el test de MannKendall apunta tendencias positivas para las temperaturas medias de Maringá y Florianópolis y para las medias de las mínimas de Londrina. Fue verificada una correlación temporal entre la eclosión de casos de dengue después de períodos lluviosos y temperaturas medias entre 17 y $27^{\circ} \mathrm{C}$ y que las condiciones climáticas de Florianópolis tiene contribuido para dificultar la reproducción y sobrevivencia del vector de la dengue.

Palabras-clave: Tendencias climáticas; Dengue; sur de Brasil.

\section{LES TENDANCES CLIMATIQUES ET LES INCIDENCES DE LA DENGUE DANS DES VILLES DU SUD DU BRÉSIL: ÉTUDE DE CAS À LONDRINA, MARINGÁ (PR) ET FLORIANÓPOLIS (SC).}

Résumé : Dans la conjoncture actuelle, la dengue est un problème majeur de santé publique au Brésil et dans le monde, étant donnée les centaines de milliers de victimes atteintes par cette maladie annuellement et saisonnièrement. Cet article vise principalement à analyser l'évolution du climat dans les villes de Londrina et Maringá (PR) et Florianópolis (SC) afin de comprendre la corrélation entre les conditions climatiques et l'incidence de la dengue dans le sud du Brésil. Ainsi, les données de température moyenne et précipitations ont été organisées dans des graphiques et des tableaux pour la période de 1983 à 2010 et soumis à l'analyse statistique de la régression linéaire, Mann-Kendall et Pettitt. Des graphiques ont également été conçus pour la représentation des notifications des premiers symptômes des cas de dengue, affichant aussi le total des précipitations et moyennes mensuelles thermiques pour la période de 2007 à 2010, soumis au test de corrélation de Pearson. Des tendances positives dans les précipitations de Florianópolis et Londrina, et négatives dans les précipitations de Maringá ont été observées. Et les tests de Mann-Kendall et Pettitt n'ont révélé aucun changement significatif se produisent dans les précipitations annuelles dans ces trois endroits. En ce qui concerne la variabilité des températures moyennes, la régression linéaire indique des tendances positives pour tous les endroits, alors que le test de Mann-Kendall présente des tendances positives pour les températures moyennes de Maringá et Florianópolis et pour les moyennes des températures minimales de Londrina. Il a été observé une corrélation temporelle entre l'apparition de cas de dengue après des périodes pluvieuses et des températures moyennes entre 17 et $27^{\circ}$. En outre, il a été remarqué que les conditions climatiques de Florianópolis contribuent jusqu'à présent à perturber la reproduction et la survie du vecteur de la dengue.

Mots-clés: tendances climatiques; Dengue; sud du Brésil. 


\section{INTRODUÇÃO}

Segundo Mendonça; Paula; Oliveira (2004), no momento em que vivemos, a dengue corresponde a um sério problema de saúde pública no mundo, principalmente no que diz respeito a países tropicais, pois as condições do ambiente e as falhas nas políticas públicas favorecem o desenvolvimento e aumento da proliferação do seu mosquito vetor, o Aedes aegypti.

Os mosquitos do gênero Aedes têm ampla distribuição geográfica, limitados entre as latitudes $35^{\circ} \mathrm{N}$ e $35^{\circ} \mathrm{S}$, nas regiões tropicais e subtropicais; fatores geográficos que proporcionam ao Brasil um ambiente propício à proliferação dos mosquitos e, portanto, da dengue.

Segundo o Ministério da Saúde (2002), "Os vetores são mosquitos do gênero Aedes. Nas Américas, a espécie Aedes aegypti é a responsável pela transmissão da dengue." A re-emergência dessa infecção sob a forma de Dengue Clássico, Febre Hemorrágica de Dengue e Síndrome de Choque do Dengue coloca essa virose como um dos mais graves problemas de Saúde Pública. Além disso, Tauil (2011) salienta que "[...] o Aedes aegypti é um mosquito de hábitos domésticos, que pica durante o dia e tem preferência acentuada por sangue humano."

Segundo Caramori et al., (2008) a condição ideal para a quebra de dormência do inseto está relacionada com a temperatura, que deve estar dentro de uma faixa adequada, para que ocorra a eclosão dos ovos e multiplicação de gerações. Além disso, para que possa haver oviposição é preciso superfícies livres com água limpa, normalmente encontrada em objetos deixados ao relento.

Segundo Mendonça; Paula (2002), a larva do Aedes aegypti se desenvolve onde há água limpa, parada e calor e destacam que três condições climáticas são propícias para a ação do mosquito da dengue: temperaturas entre 25 e $29^{\circ} \mathrm{C}$, chuvas intermitentes e ventos calmos.

As temperaturas cardinais para a larva do mosquito são inferiores a $5^{\circ} \mathrm{C}$ e superiores a $40^{\circ} \mathrm{C}$, letais; abaixo de $8^{\circ} \mathrm{C}$ e acima de $32^{\circ} \mathrm{C}$, inibem a sua atividade; de 24 a $28^{\circ} \mathrm{C}$, ótimas para o seu desenvolvimento; e, segundo a Campanha Contra a Dengue (2007), raramente ocorre transmissão da dengue com temperaturas abaixo de $6^{\circ} \mathrm{C}$. As temperaturas ótimas para a sua proliferação são em torno de 30 a $32^{\circ} \mathrm{C}$ e a sua transmissão ocorre, preferencialmente, com temperaturas acima de $20^{\circ} \mathrm{C}$. Diante do exposto, constata-se que os elementos climáticos, sobretudo a temperatura e a umidade, são condicionantes do desenvolvimento da larva do mosquito transmissor do vírus da dengue nos casos autóctones dessa doença. (FIOCRUZ, 2002 apud BURIOL et al., 2010)

Ainda segundo os autores citados, o mosquito, na fase alada, não suporta o frio, mas tem a capacidade de hibernar quando encontra condições favoráveis de sobrevivência, até o próximo ciclo de calor, podendo resistir até 500 dias.

Sobre a dinâmica do mosquito transmissor, Ferreira, Costa \& Silvestre (2008) salientam que 
Os ovos não são postos na água, e sim milímetros acima de sua superfície, em recipientes tais como latas e garrafas vazias, pneus, calhas, caixas d'água descobertas, pratos de vasos de plantas ou qualquer outro que possa armazenar água de chuva. Quando chove, o nível da água sobe, entra em contato com os ovos que eclodem em pouco mais de 30 minutos. Em um período que varia entre cinco e sete dias, a larva passa por quatro fases até dar origem a um novo mosquito.

Apesar dos condicionantes climáticos serem um ponto crucial no que diz respeito à proliferação do vírus da dengue, é preciso deixar claro que "[...] os aspectos ambientais não devem ser considerados isoladamente, sendo relevantes também as condições socioeconômicas e culturais das populações residentes nas localidades onde o número de focos do vetor é elevado" (MENDONÇA, PAULA; OLIVEIRA, 2004).

Diante da expansão espacial desta doença para áreas consideradas, até recentemente, como indenes, o presente trabalho tem como principal objetivo analisar as tendências climáticas nas cidades de Londrina e Maringá, localizadas no estado do Paraná e Florianópolis, em Santa Catarina, com o intuito de compreender a correlação das condições climáticas com a incidência da dengue no sul do Brasil. Vale destacar que os resultados ora apresentados constituem parte das análises desenvolvidas dentro de um projeto mais amplo, intitulado "Contingências socioambientais da dinâmica espacial da dengue no centro-sul do Brasil: riscos e vulnerabilidades face à urbanização e mudanças climáticas". Destaca-se que as cidades selecionadas para a análise fazem parte de um grupo daquelas que já registraram epidemias de dengue, inseridas no domínio climático subtropical úmido.

\section{MATERIAL E MÉTODOS}

Para o desenvolvimento desse estudo, primeiramente, foi necessária a aquisição de dados meteorológicos de boa qualidade e numa sequência contínua, imprescindíveis para o desenvolvimento de estudos de variabilidade climática. Os dados de precipitação total e das temperaturas médias (mínimas, médias e máximas) foram disponibilizados para os recortes temporais mensais e anuais para o período de 27 anos (1983 a 2010) pelo Instituto Agronômico do Paraná (IAPAR) para a cidade de Londrina, pelo Instituto Nacional de Meteorologia (INMET) para Maringá (PR) e pela Empresa de Pesquisa Agropecuária e Extensão Rural de Santa Catarina (EPAGRI) para Florianópolis (SC). Destaca-se que o referido recorte temporal foi definido em virtude da disponibilidade dos dados para a localidade de Florianópolis e por ser um período que não apresentou falhas.

Para a análise e interpretação dos dados foram elaborados gráficos de distribuição anual das temperaturas médias e dos totais anuais das precipitações, desenvolvidos por meio da planilha eletrônica Excel; bem como para o cálculo da regressão linear. E a partir do software XLSTAT foram aplicados os testes estatísticos de Mann-Kendall e Pettitt com o intuito de 
verificar a existência de tendências e rupturas na evolução das temperaturas e precipitações. Segundo Back (2001), o teste de Mann-Kendall é o método mais apropriado para analisar mudanças climáticas em séries climatológicas e também permite a detecção e localização aproximada do ponto inicial de determinada tendência. Enquanto que o teste de Pettitt permite localizar o ponto onde houve uma mudança brusca na média de uma série temporal de dados.

Os dados dos casos de dengue foram disponibilizados pela Secretaria da Saúde do estado do Paraná (SESA) e pela Secretaria Municipal de Saúde de Florianópolis (SC). Para a presente análise foram considerados os dados de identificação dos municípios, a data dos primeiros sintomas para os casos autóctones e importados que foram plotados em gráficos juntamente com os totais pluviométricos e as temperaturas médias mensais para os anos de 2007, 2008, 2009 e 2010. Esse recorte temporal foi definido em virtude da disponibilidade dos dados e pelo fato de compreender dois períodos que se configuraram em epidemias de dengue no estado do Paraná (DUQUE, 2010). A partir do software XLSTAT foi aplicado o teste de Pearson para esse conjunto de dados.

\section{RESULTADOS E DISCUSSÕES}

Londrina está localizada na região norte do estado do Paraná (figura 1), nas seguintes coordenadas geográficas: $23^{\circ} 22^{\prime}$ de latitude Sul e 51010' de longitude a Oeste, em uma altitude média de $585 \mathrm{~m}$, com uma área territorial de $1.650 \mathrm{~km}^{2}$ e população estimada de 506.701 mil habitantes, com uma densidade demográfica de aproximadamente 306,49 hab/km² (IBGE, 2010).

A cidade de Maringá está localizada na região noroeste do estado do Paraná (figura 1), na latitude de 23025' Sul e longitude de 51057' Oeste, com uma altitude média de $596 \mathrm{~m}$. O município possui a extensão territorial de $488 \mathrm{~km}^{2}$ com uma população de 357.077 mil habitantes e densidade demográfica de $732,12 \mathrm{hab} / \mathrm{km}^{2}$ (IBGE,2010).

A cidade de Florianópolis (figura 1), capital do estado de Santa Catarina, está situada no litoral, na latitude de $27^{\circ} 35^{\prime}$ Sul e longitude de $48^{\circ} 32^{\prime}$ Oeste com altitude média de $3 \mathrm{~m}$. Possui 421.240 mil habitantes e densidade demográfica de 627,24 hab/ $\mathrm{km}^{2}$, em uma área territorial de $672 \mathrm{~km}^{2}$ (IBGE, 2010).

Segundo a classificação climática de Köppen, o clima predominante nos três municípios é o subtropical úmido ( $\mathrm{Cfa}$ ) com temperatura média no mês mais frio inferior a $18^{\circ} \mathrm{C}$ (mesotérmico) e temperatura média no mês mais quente acima de $22^{\circ} \mathrm{C}$, com verões quentes, geadas pouco frequentes e tendência de concentração das chuvas nos meses de verão, contudo sem estação seca definida (IAPAR, 2011). 


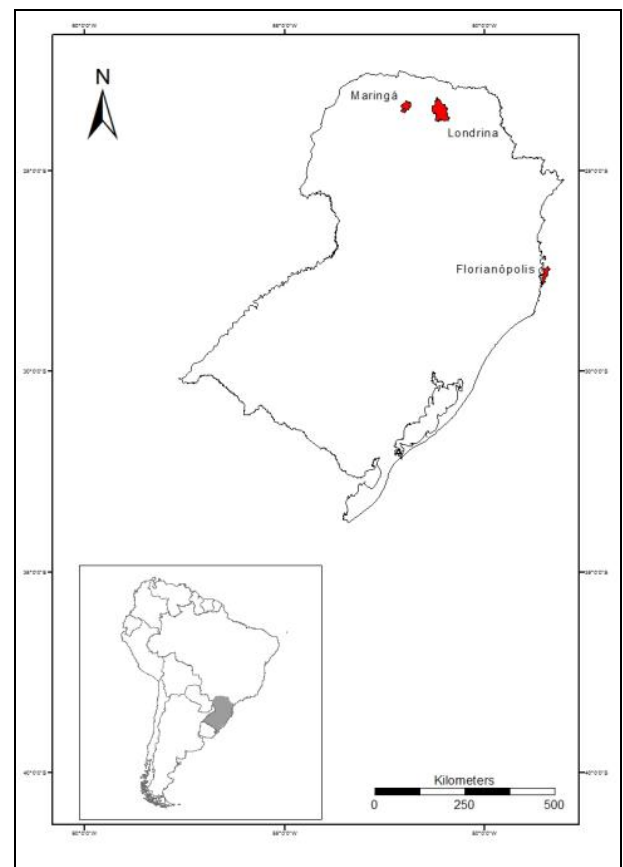

Figura 1. Localização dos municípios de Londrina, Maringá (PR) e Florianópolis (SC).

(Elaborado pela autora)

a) Variabilidade climática

Na figura 2 estão representados os totais pluviométricos anuais do período em estudo para os municípios analisados e foi identificado um padrão cíclico na variação dos mesmos. O ano de 1983 registrou totais acima da média (maiores que $2100 \mathrm{~mm}$ ) em todas as localidades. No período de 1984 a 1996 as precipitações permaneceram próximas à média histórica, mas o ano de 1988 foi caracterizado por baixo total pluviométrico nos três municípios; sendo que em Florianópolis a redução foi mais expressiva, com mais de $700 \mathrm{~mm}$ abaixo da média. Os anos de 1997 e 1998 registraram totais acima de 1800mm nas localidades consideradas, refletindo a influência de um fenômeno El Niño de forte intensidade (CPTEC, 2012); enquanto que o ano de 1999 apresentou menores totais (em torno de $1200 \mathrm{~mm}$ anuais). No período de 2000 a 2008 os totais pluviométricos variaram próximos à média nas três localidades, mas em Florianópolis os anos de 2001 e 2008 apresentaram totais mais elevados $(2360,7 \mathrm{~mm}$ e $2887,9 \mathrm{~mm}$ respectivamente). Enquanto que em Londrina e Maringá o ano de 2009 concentrou os maiores totais $(2333,5$ e 2171,2mm respectivamente).

O fato de Florianópolis estar localizada numa ilha e banhada pelo oceano Atlântico pode justificar sua distinta variabilidade pluviométrica, devido à maior disponibilidade de umidade relativa do ar; assim como a diferença no volume total anual de chuvas em relação aos outros municípios. O que fica bastante evidente ao compararmos a média de precipitação pluviométrica total do 
período, pois em Florianópolis a média histórica é de $1793 \mathrm{~mm}$ e em Londrina e Maringá é de $1597 \mathrm{~mm}$ e $1636 \mathrm{~mm}$, respectivamente.

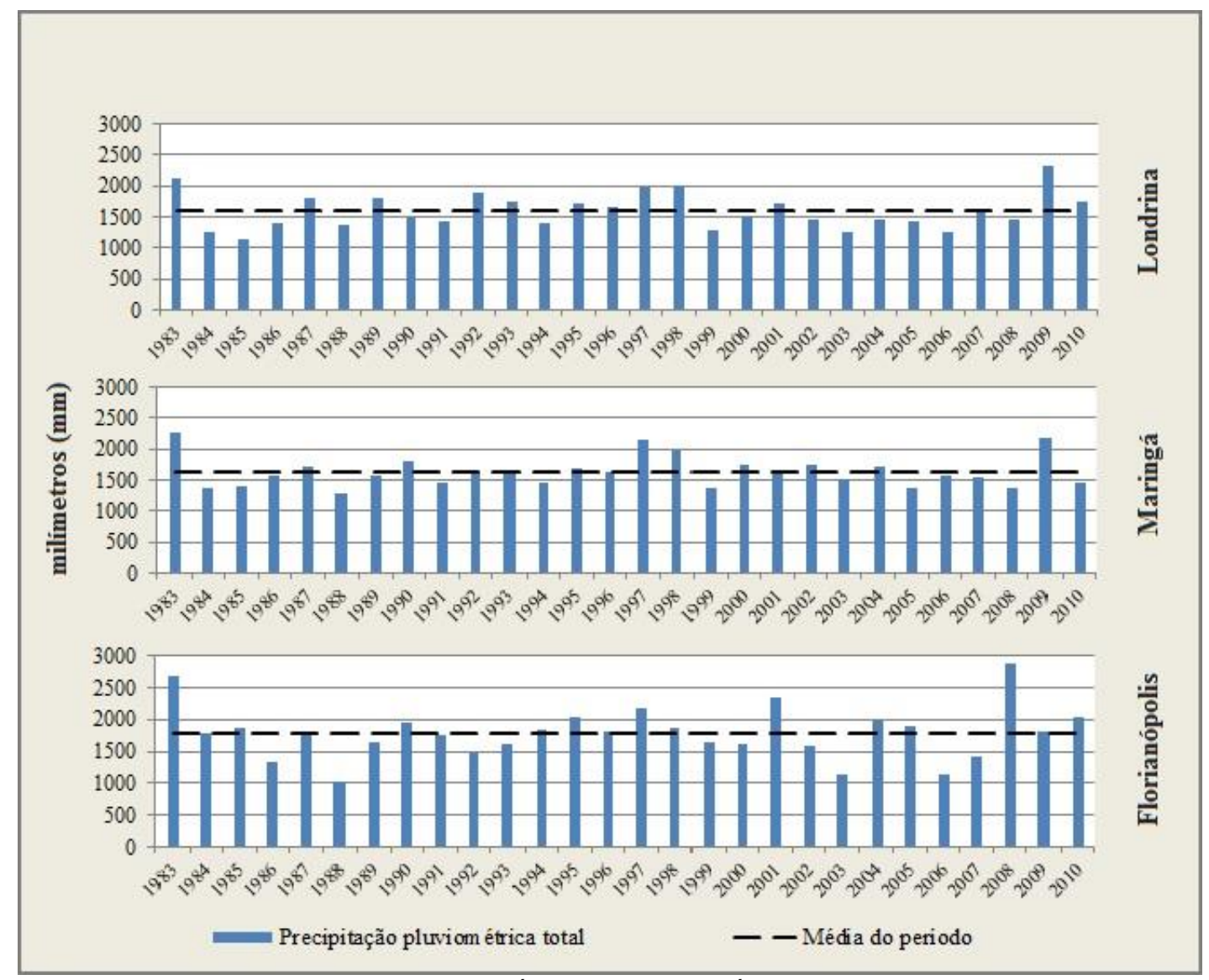

Figura 2. Total pluviométrico anual no período de 1983 a 2010.

Fonte: IAPAR, INMET e EPAGRI. (Elaborado por OLIVEIRA, L. T. de e BERTINI, I. T.)

Com relação aos resultados dos testes estatísticos (tabela 1), a regressão linear indica uma tendência positiva das precipitações no período de 1983 a 2010 em Londrina e Florianópolis, mas negativa para Maringá. Enquanto que os testes de Mann-Kendall e Pettitt revelaram não ocorrer mudanças significativas nas precipitações anuais dos três municípios.

Tabela 1. Resultados dos testes estatísticos para a variabilidade da precipitação anual no período de 1983 a 2010.

\begin{tabular}{l|c|c|c}
\hline Precipitação & $\begin{array}{c}\text { Regressão } \\
\text { Linear }\end{array}$ & Mann-Kendall & Pettitt \\
\hline Londrina & 2,1063 & 0,891 & 0,896 \\
\hline Maringá & $-0,4557$ & 0,984 & 0,834 \\
\hline Florianópolis & 2,9522 & 0,681 & 0,783 \\
\hline \multicolumn{3}{c}{ (Elaborado pela autora) }
\end{tabular}

No tocante às temperaturas médias anuais do período, na figura 3 são verificadas diferenças entre as localidades analisadas. A temperatura média apresentada por Maringá foi mais alta $\left(23,3^{\circ} \mathrm{C}\right)$ do que em Londrina $\left(21,2^{\circ} \mathrm{C}\right)$ e 
em Florianópolis $\left(20,8^{\circ} \mathrm{C}\right)$; demonstrando a influência da variação latitudinal das mesmas.

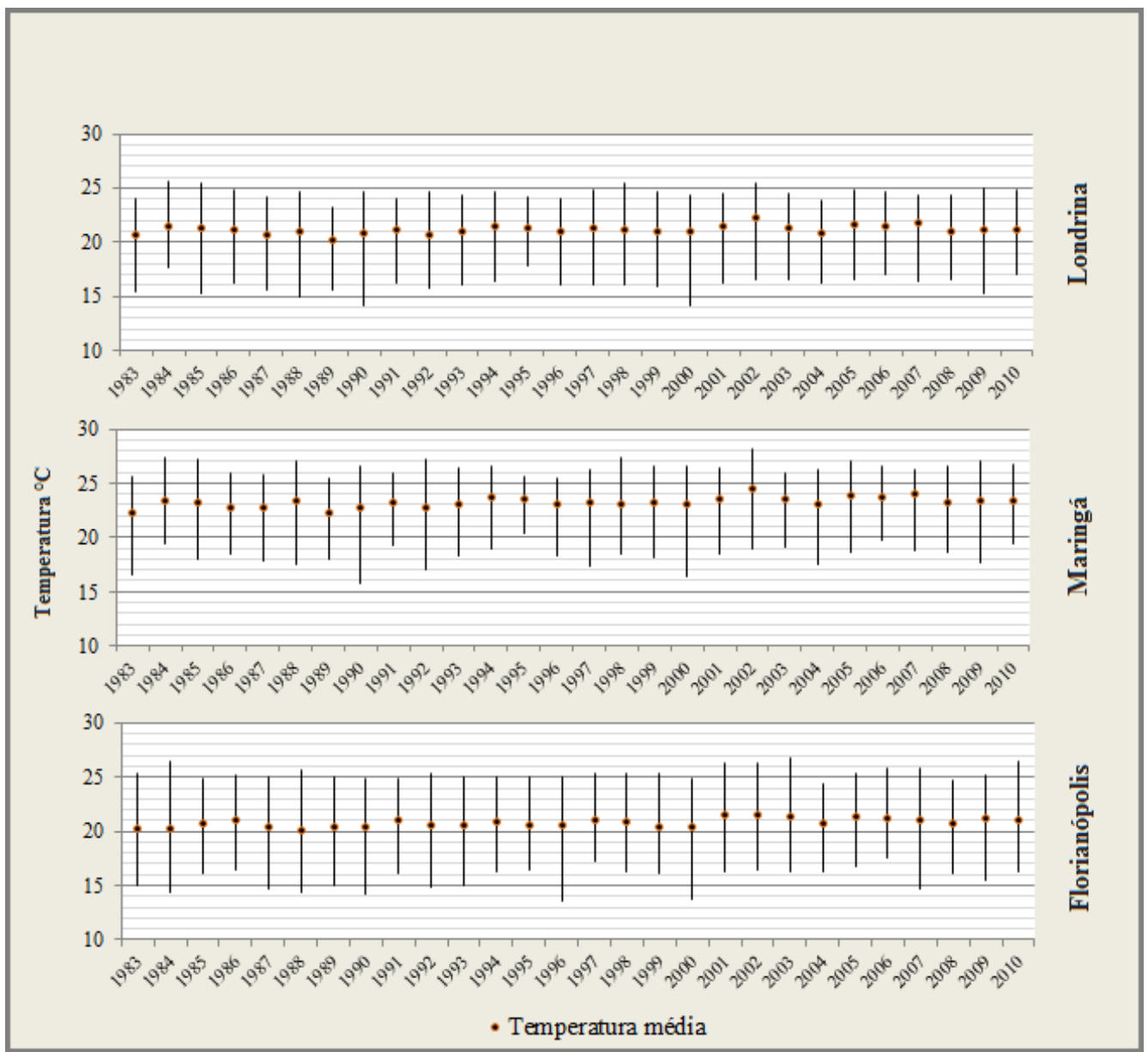

Figura 3. Temperatura média anual no período de 1983 a 2010.

Fonte: IAPAR, INMET e EPAGRI. (Elaborado por OLIVEIRA, L. T. de e BERTINI, I. T.)

Em Maringá, em todos os 27 anos da série histórica, as temperaturas médias máximas estiveram acima dos $25,4^{\circ} \mathrm{C}$, o que só ocorreu em Londrina em 4 anos (1984, 1998 e 2002). Em Florianópolis isto ocorreu em 8 dos 27 anos (1984, 1988, 2001, 2002, 2003, 2006, 2007 e 2010) e, a partir de 2001, percebe-se um aumento considerável das temperaturas médias, máximas e mínimas nesta localidade.

Os registros das temperaturas médias mínimas em Londrina ficaram próximos de $16^{\circ} \mathrm{C}$, em média, havendo alguns anos extremos que registraram $14,1^{\circ} \mathrm{C}$ (1990 e 2000). Em Maringá a temperatura média mínima do período foi de $18,2^{\circ} \mathrm{C}$, superior aos outros municípios; os casos extremos também foram registrados em 1990 e 2000, com temperaturas médias mínimas de $15,7^{\circ} \mathrm{C}$ e $16,4^{\circ} \mathrm{C}$, respectivamente. Pode-se perceber que em Florianópolis as temperaturas médias mínimas foram inferiores em relação aos outros dois municípios, sendo de $15,6^{\circ} \mathrm{C}$ em média, com eventos mais severos nos anos de 1984, 1988, 1990, 1996 e 2000; todos com temperaturas médias mínimas 
abaixo dos $15^{\circ} \mathrm{C}$, sendo que em 1996 e 2000 a média mínima foi inferior a $14^{\circ} \mathrm{C}$.

Essa distinção entre as temperaturas nas três localidades pode ser explicada pela influência de diversos controles climáticos, tais como a localização, o relevo, a continentalidade, a maritimidade e a atuação dos diferentes sistemas atmosféricos. De um modo geral, Maringá apresenta temperaturas mais elevadas; enquanto que em Londrina predominam as características de transição climática. Mas destaca-se que Londrina apresenta temperatura média máxima inferior àquela de Florianópolis e temperatura média mínima superior a esta última. Diante disso, constata-se que Florianópolis é a localidade que possui maior amplitude térmica anual $\left(13,3^{\circ} \mathrm{C}\right)$, reforçando a influência da posição latitudinal das localidades.

No tocante a verificação de tendências na variabilidade das temperaturas médias, a regressão linear indica tendências positivas para todas as localidades; enquanto que o teste de Mann-Kendall aponta tendências positivas apenas para as temperaturas médias de Maringá e Florianópolis e para as médias das mínimas de Londrina (tabela 2). Mas o teste de Pettitt revela que não ocorreram mudanças significativas nas médias das mínimas das três localidades, indicando uma ruptura positiva nas médias das máximas de Maringá e nas temperaturas médias de Florianópolis.

Tabela 2. Resultados dos testes estatísticos para a variabilidade das temperaturas no período de 1983 a 2010.

\begin{tabular}{l|c|c|c|c|c|c|c|c|c}
\hline & \multicolumn{4}{|c}{ Regressão Linear } & \multicolumn{3}{c}{ Mann-Kendall } & \multicolumn{3}{c}{ Pettitt } \\
\cline { 2 - 10 } & Tmax & Tmed & Tmin & Tmax & Tmed & Tmin & Tmax & Tmed & Tmin \\
\hline Londrina & 0,0015 & 0,019 & 0,0264 & 0,781 & 0,086 & 0,015 & 0,700 & 0,062 & 0,062 \\
\hline Maringá & 0,0141 & 0,0328 & 0,0383 & 0,351 & 0,003 & 0,097 & 0,005 & 0,394 & 0,247 \\
\hline Florianópolis & 0,0171 & 0,0302 & 0,0496 & 0,313 & 0,002 & 0,055 & 0,291 & 0,001 & 0,072 \\
\hline
\end{tabular}

(Elaborado pela autora)

\section{b) Dengue e elementos climáticos}

Foram registrados casos de primeiros sintomas de dengue durante todo o ano de 2007 em Londrina (PR) (figura 4), porém, no período de fevereiro a maio ocorreu uma concentração maior, com 743 casos; destacando-se que, durante o ano todo, foram registrados 853 casos. A concentração dos casos entre os meses de fevereiro a maio é explicada pela própria dinâmica do mosquito transmissor, que necessita de períodos chuvosos intermitentes e de temperaturas elevadas (entre 24 e $27^{\circ} \mathrm{C}$ ) para se reproduzir. As temperaturas médias e os totais de precipitação nestes meses permaneceram elevados em Londrina: $24,2^{\circ} \mathrm{C}$ e $180,8 \mathrm{~mm}$ (Fevereiro), $24,3^{\circ} \mathrm{C}$ e $138,2 \mathrm{~mm}$ (Março), $22,9^{\circ} \mathrm{C}$ e $38,8 \mathrm{~mm}$ (Abril) e $18,2^{\circ} \mathrm{C}$ e $69,3 \mathrm{~mm}$ (Maio), propiciando boas condições para a eclosão dos ovos, para a ação e proliferação dos mosquitos Aedes aegypti. A partir de junho o número de casos diminui significativamente, quando as temperaturas e a precipitação também entram em declínio.

Em 2008 e 2009 também foram registrados casos de dengue durante o decorrer de todos os anos em Londrina e a maior concentração também ocorreu 
nos meses de fevereiro a maio; porém nos referidos anos os casos tiveram forte redução, com um total anual de 150 e 109 casos, respectivamente.

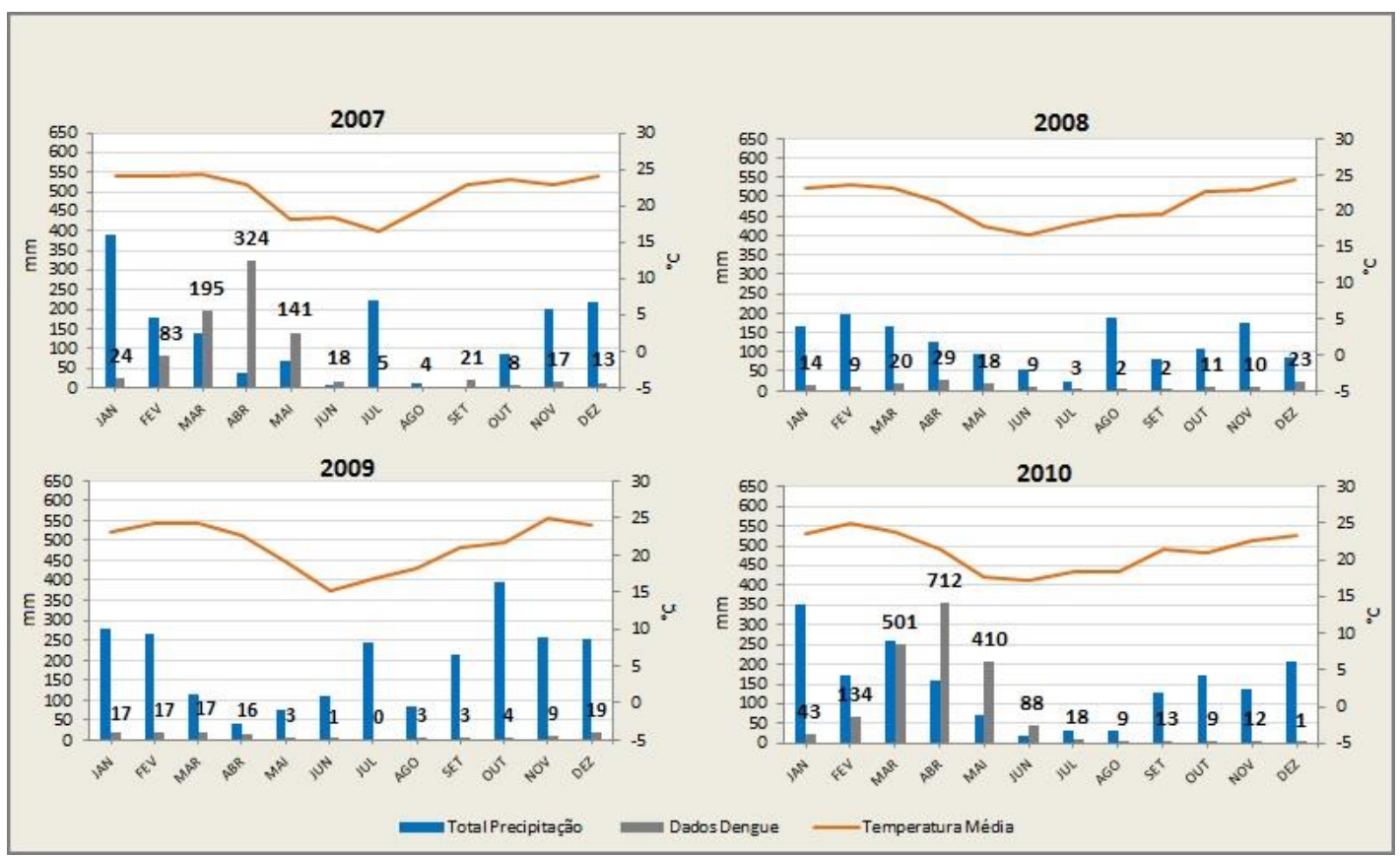

Figura 4. Temperatura média, precipitação e número de casos de primeiros sintomas de degue em Londrina (PR), no período de 2007 a 2010.

Fonte: IAPAR e SESA. (Elaborado por OLIVEIRA, L. T. de e BERTINI, I. T.)

O ano de 2010 apresentou um aumento nos casos de dengue em Londrina, com um total anual de 1950 casos. O mês de fevereiro demarca o início do aumento no número de casos, atingindo o ápice no mês de abril e redução a partir de junho. As temperaturas médias e os totais de precipitação também permaneceram altos nesse ano: $24,9^{\circ} \mathrm{C}$ e $171,7 \mathrm{~mm}$ (Fevereiro); $23,8^{\circ} \mathrm{C}$ e $257,7 \mathrm{~mm}$ (Março); $21,4^{\circ} \mathrm{C}$ e $159,9 \mathrm{~mm}$ (Abril); $17,7^{\circ} \mathrm{C}$ e $71,4 \mathrm{~mm}$ (Maio).

Vale destacar que, exceto para o ano de 2009, o mês de abril foi o que concentrou o maior número de casos: 324 (2007), 29 (2008), 712 (2009).

A cidade de Maringá (PR) apresenta uma dinâmica semelhante à de Londrina (PR) (figura 5), o ano de 2007 também foi caracterizado como um ano epidêmico, com um total de 5715 casos registrados de primeiros sintomas de dengue. $\mathrm{E}$, assim como em Londrina, o maior número de notificações ocorreu no período de fevereiro a maio, totalizando 5537 casos. Vale ressaltar que as temperaturas médias e os totais pluviométricos desses meses caracterizam o ambiente ideal para a ação do mosquito: $25,9^{\circ} \mathrm{C}$ e $207,4 \mathrm{~mm}$ (Fevereiro); $26,2^{\circ} \mathrm{C}$ e $150,0 \mathrm{~mm}$ (Março); $25^{\circ} \mathrm{C}$ e $63,9 \mathrm{~mm}$ (Abril); $20,3^{\circ} \mathrm{C}$ e $51,4 \mathrm{~mm}$ (Maio). 


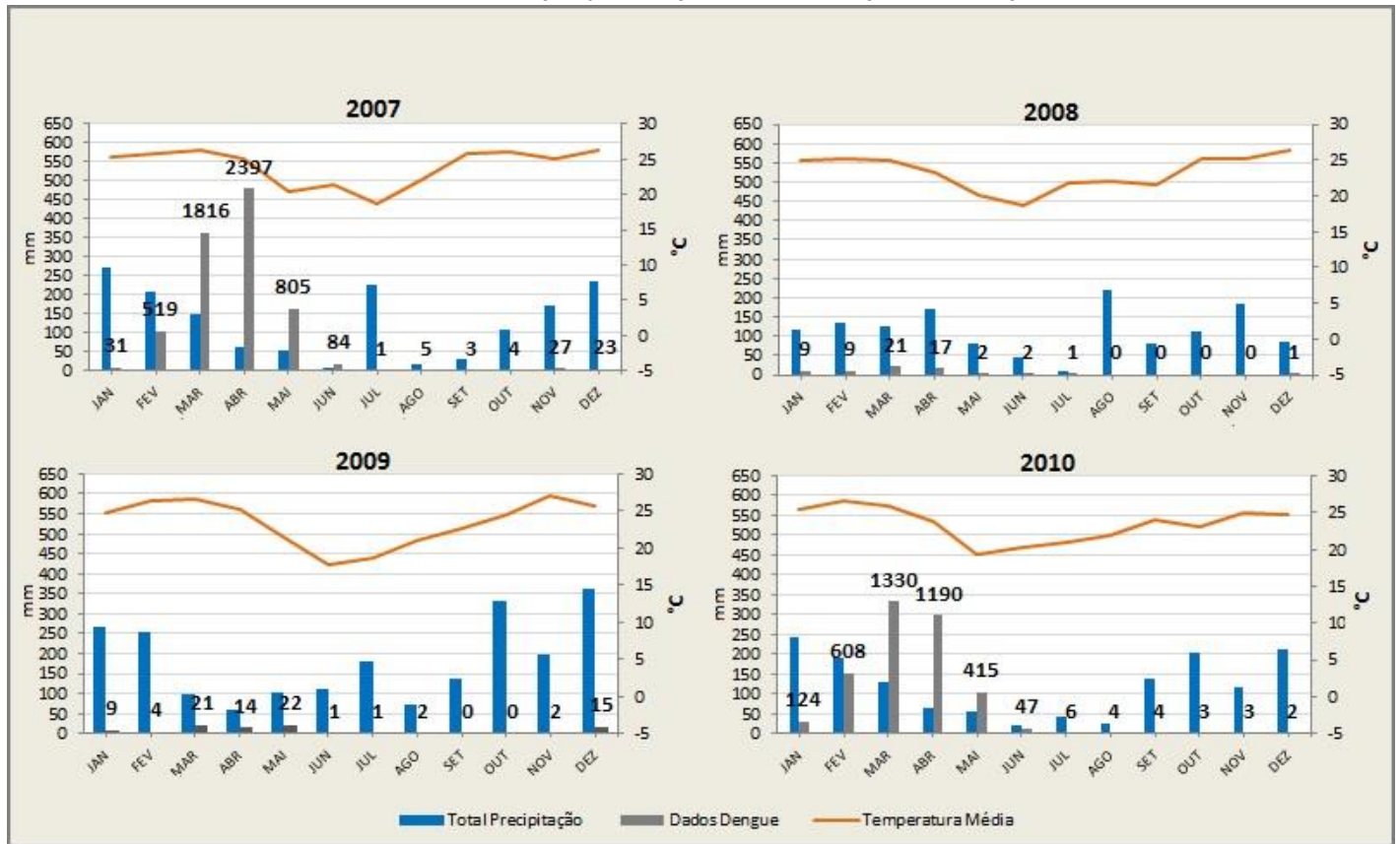

Figura 5. Temperatura média, precipitação e número de casos de primeiros sintomas de degue em Maringá (PR), no período de 2007 a 2010.

Fonte: INMET e SESA. (Elaborado por OLIVEIRA, L. T. de e BERTINI, I. T.)

Nos anos de 2008 e 2009 as notificações dos casos de primeiros sintomas de dengue tiveram forte redução em Maringá; com um total anual de 62 e 91 casos, respectivamente. Destaca-se que os totais pluviométricos mensais não variaram muito de um ano para outro, assim como as temperaturas médias.

Assim como em Londrina, o ano de 2010 registrou um expressivo aumento no número de notificações de casos de dengue em Maringá, com um total de 3736 casos. Verifica-se uma repetição da dinâmica apresentada em Londrina, ou seja, após um período chuvoso a precipitação diminui e a temperatura se mantém entre 17 e $27^{\circ} \mathrm{C}$ produzindo as condições ótimas para a eclosão dos ovos, transmissão e proliferação da dengue pelos mosquitos. Bem como os meses de fevereiro, março, abril e maio concentraram os casos de dengue em Maringá (608 casos em fevereiro; 1330 em março; 1190 em abril e 415 em maio), sendo que abril foi o mês com maior número de casos tanto em 2007 como em 2010.

Florianópolis (SC), localizada $5^{\circ}$ de latitude mais ao Sul que Londrina e Maringá (PR), não demonstrou números expressivos nos registros de casos de primeiros sintomas de dengue para a série analisada (figura 6); mesmo assim os anos de 2007 e 2010 também concentraram o maior número: 16 casos em 2007 e 25 notificações em 2010. Apesar de apresentar temperaturas propícias para o desenvolvimento e ação do mosquito transmissor (entre $17,5^{\circ} \mathrm{C}$ e $26,5^{\circ} \mathrm{C}$ ) no período entre fevereiro e maio, em Florianópolis, as chuvas foram contínuas e com totais elevados (de 134,2 a 252,5mm); não permitindo a eclosão dos ovos, pois não se estabelece o intervalo de redução das precipitações necessário para que a mesma ocorra. Além disso, destaca-se que os casos de primeiros sintomas de dengue registrados na cidade são importados, ou seja, a 
transmissão não ocorreu na cidade. Desta forma, percebe-se que, além da grande importância que a precipitação e as temperaturas exercem sobre a propagação da doença, outros fatores também precisam ser considerados para entender a dinâmica do mosquito e da doença nesta área.

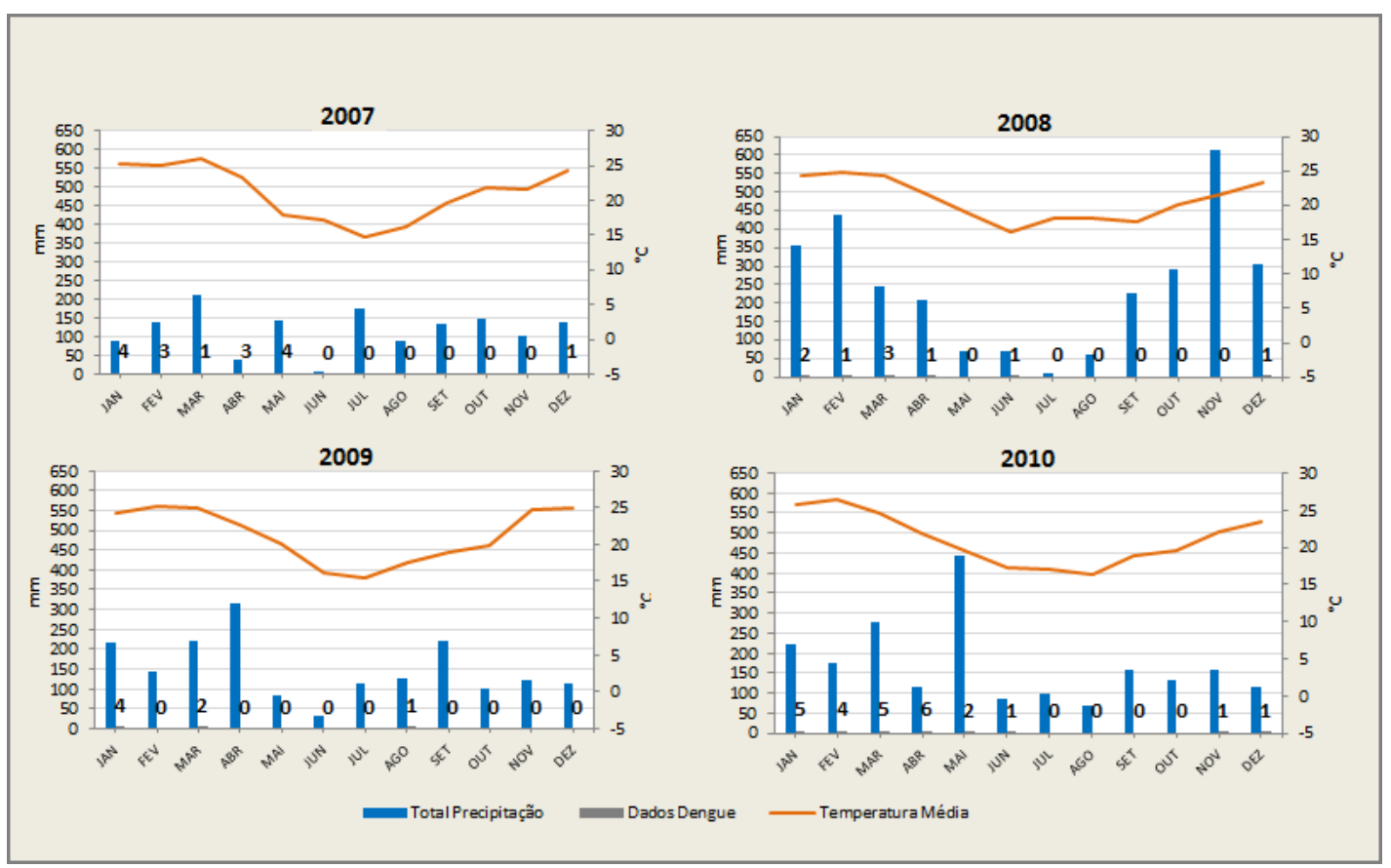

Figura 6. Temperatura média, precipitação e número de casos de primeiros sintomas de degue em Florianópolis (SC), no período de 2007 a 2010.

Fonte: EPAGRI e Secretaria Municipal de Saúde de Florianópolis (SC). (Elaborado por OLIVEIRA, L. T. de e BERTINI, I. T.)

Com o intuito de medir a correlação do número de casos de primeiros sintomas de dengue com a temperatura média e o total pluviométrico mensal foi aplicado o teste de Pearson (tabela 3), que demonstrou ocorrer fraca correlação dos casos mensais de dengue com as temperaturas médias mensais para Londrina e Maringá; mas moderada correlação para Florianópolis. E a correlação com os totais mensais de precipitação é negativa para Londrina e Maringá e positiva para Florianópolis; porém uma correlação fraca.

Tabela 3 - Resultados do teste de Pearson

\begin{tabular}{l|l|c|c|c}
\hline & Variáveis & Casos & Valor-p & $\mathbf{R}^{\mathbf{2}}$ \\
\hline \multirow{2}{*}{ Londrina } & $\begin{array}{l}\text { Temp } \\
\text { média }\end{array}$ & 0,072 & 0,627 & 0,51834789 \\
\cline { 2 - 5 } & Precipitação & $-0,019$ & 0,896 & 0,03731203 \\
\hline \multirow{2}{*}{ Florianópó } & $\begin{array}{l}\text { Temp } \\
\text { média }\end{array}$ & 0,175 & 0,235 & 3,05490902 \\
\cline { 2 - 5 } & Precipitação & $-0,131$ & 0,376 & 3,05490902 \\
\hline & $\begin{array}{l}\text { Temp } \\
\text { média }\end{array}$ & 0,491 & 0,000 & 24,1512606 \\
\cline { 2 - 5 } & Precipitação & 0,123 & 0,404 & 1,51879893 \\
\hline
\end{tabular}




\section{CONSIDERAÇÕES FINAIS}

A análise dos dados pluviométricos possibilitou constatar a ocorrência de semelhanças na variabilidade das chuvas em Londrina e Maringá (PR), mas em Florianópolis essa variação se dá de forma distinta devido à sua posição latitudinal e a influência da maritimidade que propiciam um volume maior das chuvas e uma melhor distribuição anual das mesmas. Destaca-se que, para o período de 1983 a 2010, a regressão linear indica uma tendência positiva das precipitações para Londrina e Florianópolis; porém negativa para Maringá. Mas os testes de Mann-Kendall e Pettitt revelaram não ocorrer mudanças significativas nas precipitações anuais dos três municípios.

Com relação à variabilidade térmica apresentada pelas localidades, Maringá registrou a maior média $\left(23,3^{\circ} \mathrm{C}\right)$, seguida por Londrina $\left(21,2^{\circ} \mathrm{C}\right)$ e Florianópolis $\left(20,8^{\circ} \mathrm{C}\right)$; demonstrando a influência da variação latitudinal das mesmas. Florianópolis apresentou a maior amplitude térmica anual $\left(13,3^{\circ} \mathrm{C}\right)$, reforçando a influência da latitude. No tocante às tendências para a variabilidade das temperaturas médias, a regressão linear indica tendências positivas para todas as localidades; enquanto que o teste de Mann-Kendall aponta tendências positivas para as temperaturas médias de Maringá e Florianópolis e para as médias das mínimas de Londrina.

Assim, conclui-se que as temperaturas das localidades estudadas têm demonstrado uma elevação, contribuindo para o aumento no número de casos de primeiros sintomas de dengue, visto que o vetor desta doença necessita de temperaturas elevadas e precipitação pluviométrica intermitente. Portanto, a situação ambiental das mesmas é propícia para a eclosão dos ovos, ação e proliferação dos mosquitos Aedes aegypti.

A análise da dengue correlacionada aos elementos climáticos possibilitou identificar o período de fevereiro a maio como o mais propício para a eclosão dos ovos, ação e proliferação dos mosquitos Aedes aegypti; pois demonstra um período de redução dos totais pluviométricos posterior a um período chuvoso com as temperaturas médias se mantendo entre 17 e $27^{\circ} \mathrm{C}$.

Abril foi o mês com maior eclosão dos casos de primeiros sintomas de dengue nas localidades estudadas, momento em que os totais pluviométricos reduzem (90 $\mathrm{mm}$ em média) mas com temperaturas médias entre $21^{\circ} \mathrm{C}$ e $24^{\circ} \mathrm{C}$.

A identificação desse período ótimo para a eclosão dos ovos, ação e proliferação dos mosquitos é de grande importância para as ações de combate aos mesmos; pois os agentes de combate à dengue podem intensificar as visitas às residências no período chuvoso (dezembro e janeiro) para eliminar os possíveis criadouros; além de intensificar as campanhas de conscientização da população para a eliminação dos mesmos.

A análise temporal das notificações dos casos de primeiros sintomas de dengue nas localidades estudadas indica 2007 e 2010 como anos epidêmicos para Londrina e Maringá (PR), com uma redução dos casos nos anos de 2008 e 2009. Duque et al (2010) destacam que 2006 / 2007 demarca um período de co-circulação dos sorotipos do vírus da dengue DEN1, DEN2 e DEN3 no Paraná, a população estava parcialmente imune à algumas das variações do vírus e a dispersão do vetor não foi acompanhada de vigilância epidemiológica; 
proporcionando a elevação no contato hospedeiro vetor. Os autores também enfatizam o padrão de comportamento da dengue em ondas epidêmicas que provocam ampla distribuição dos casos seguidas de um período de redução, pois o vetor sofre uma adaptação e a população se torna imune ao vírus em circulação. Após o período de redução, devido à flexibilidade do vírus, ele passa por modificações e circula novamente, gerando novas epidemias como a de 2010.

A aplicação do teste de Pearson na correlação do número mensal de casos de primeiros sintomas de dengue com as temperaturas médias indicou fraca correlação para Londrina e Maringá; mas moderada correlação para Florianópolis e fraca correlação com os totais mensais de precipitação para essa última. Ou seja, um menor número de casos de dengue com temperaturas mais amenas e com maiores volumes e melhor distribuição das chuvas, indicando que as condições climáticas de Florianópolis têm contribuído, até agora, para dificultar a reprodução e sobrevivência do vetor; já que os casos identificados para esta localidade são importados.

\section{REFERÊNCIAS BIBLIOGRÁFICAS}

BACK, J. Á. Aplicação de análise estatística para identificação de tendências climáticas.

Pesquisa Agropecuária Brasileira. Brasília, v.36, n.5, maio/2001. p. 717-726

BURIOL, G. A. et al. Zoneamento climático das condições para o desenvolvimento da larva do mosquito transmissor do vírus da dengue no Estado do Rio Grande do Sul.

Revista Eletrônica de Comunicação, Informação \& Inovação em Saúde - RECIIS. Rio de Janeiro, v. 3, n. 2, p. 24 - 36, Jun. 2009. Disponível em: <http://www.reciis.cict.fiocruz.br/index.php/reciis/article/viewArticle/146>. Acesso em: 28 ago. 2012.

CARAMORI, P. H. et al. Potencial de propagação do Aedes aegypti no estado do Paraná sob cenários de mudanças climáticas. In: Simpósio Brasileiro de Climatologia Geográfica, 8, 2008. Alto Caparaó. Anais. Alto Caparaó. Universidade Federal de Uberlândia. 2008. CD-Rom. p. 170 - 178

CPTEC. CENTRO DE PREVISÃO DO TEMPO E ESTUDOS CLIMÁTICOS. Disponível em: <http://enos.cptec.inpe.br/tab_elnino.shtml>. Acesso em: jul. 2012.

DUQUE, J. E. et al. Dengue no Estado do Paraná, Brasil: distribuição temporal e espacial no período de 1995-2007. Revista Salud UIS. Bucaramanga - Colômbia, v. 42, n. 2, p. 1132 122, 2010.2 Disponível em: <http://revistas.uis.edu.co/index.php/revistasaluduis/article/view/1396>. Acesso em: 28 ago. 2012.

ELY, D. F.; BERTINI, I. T.; OLIVEIRA, L. T. De; Variabilidade climática nas cidades de Londrina, Maringá (PR) e Florianópolis (SC) e a expansão latitudinal da dengue. REVISTA GEONORTE. Manaus (AM), Edição Especial 2, v. 2, n. 5, p. 826 - 839, 2012.

FERREIRA, A. B.; COSTA, F. P. M.; SILVESTRE, K. B. Índice vetorial da cidade de Uberlândia - MG para Aedes Aegypti em função da variação climática para o ano de 2002. In: Simpósio Brasileiro de Climatologia Geográfica, 8, 2008, Alto Caparaó. CD-ROM. p. 109 - 118.

IAPAR. INSTITUTO AGRONOMICO DO PARANÁ. Cartas Climáticas do Paraná. 2011. Disponível em: <http://www.iapar.br/modules/conteudo/conteudo.php?conteudo=863>. Acesso em: jul. 2012.

IBGE. INSTITUTO BRASILEIRO DE GEOGRAFIA E ESTATISTICAS. Ibge Cidades. Disponível em: < http://www.ibge.gov.br/cidadesat/topwindow.htm?1>. Acesso em: 15 ago. 2012.

MENDONÇA, F. A.; DANNI-OLIVEIRA, I.M. Climatologia - Noções básicas e climas do Brasil. São Paulo: Oficina de textos, 2007. 
MENDONÇA, F.; PAULA, E. V.; OLIVEIRA, M. M. F. Aspectos sócios-ambientais da expansão da dengue no Paraná. In: ENCONTRO DO ANPPAS, 2, 2004, Indaiatuba. Disponível em: <http://www.anppas.org.br/encontro/segundo/papers/ papers.html\#2>. Acesso em: jul. 2012.

MENDONÇA, F.; PAULA, S.V. de. Análise geográfica da dengue no Paraná e em Curitiba no período 1995-2002: um enfoque climatológico. In: Simpósio Brasileiro de Climatologia Geográfica, 5, 2002, Curitiba. CD-ROM.

MENDONÇA, F.; PAULA, S.V. de; OLIVEIRA, M.M.F de. Aspectos sócio-ambientais da expansão da dengue no Paraná. Disponível em: <http://www.anppas.org.br/encontro_anual/encontro2/GT/gt12/anpas_dengue.pdf>. Acesso em: jul. 2012.

MINISTÉRIO DA SAÚDE. Dengue: Aspectos Epidemiológicos, Diagnostico e Tratamento. Brasília: Editora MS, 2002.

SECRETARIA DE ESTADO DA SAÚDE DO PARANA. Paraná Contra a Dengue. Disponível em: < http://www.paranacontradengue.pr.gov.br/ >. Acesso em: jul. 2012.

TAUIL, P. L. Urbanização e ecologia do dengue. Disponível em: <http://www.scielosp.org/pdf/csp/v17s0/3885.pdf>. Acesso em: jul. 2012. 